
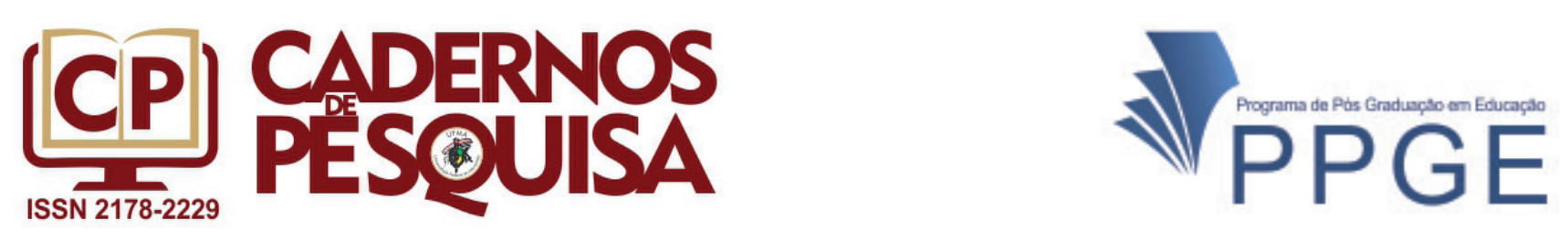

\title{
O DIÁLOGO COMO MEDIAÇÃO PEDAGÓGICA
}

\author{
DIALOGUE AS A PEDAGOGICAL MEDIATION
}

DIÁLOGO COMO MEDIACIÓN PEDAGÓGICA

Luiz Síveres

http://orcid.org/0000-0003-4735-6066

Denise Maria Soares Lima
http://orcid.org/0000-0001-5530-2282

Resumo: Em um contexto social demarcado pelos contatos, principalmente tecnológicos, em detrimento de relações mais dialogais, e em um processo educativo caracterizado por procedimentos hierárquicos, de forma mais evidenciada na interação entre professor e estudante, foi levantado o seguinte questionamento: é possível estabelecer relações dialógicas em espaços e processos monológicos? Com o objetivo de buscar uma resposta aproximada a essa problemática, realizou-se a pesquisa em uma escola pública do Distrito Federal, que investigou as percepções de adolescentes do ensino médio acerca da escola como espaço de diálogo, considerando as demandas estudantis pessoais ou coletivas. Para isso, elegeu-se a dinâmica das rodas de conversa entre os participantes. A análise dos dados que emergiram das falas dos estudantes durante a atividade foi proposta nos moldes de Bardin (2009), que sugere a análise de conteúdo. A base teórica está pautada na compreensão do diálogo como mediação pedagógica, subdividido em três aspectos: existencial, relacional e proposicional. Os resultados demonstraram que o diálogo está ausente ou é ineficiente nesse ambiente escolar, destacando-se a dificuldade de se estabelecer uma relação dialogal entre professor e aluno, ou pela restrição de acolhida e, notadamente, pela pouca importância dada à mediação pedagógica para favorecer um ambiente educativo mais dialógico no processo educativo.

Palavras-chave: Diálogo. Mediação pedagógica. Estudantes. Escola.

Abstract: In a social context marked by contacts, particularly technological, in detriment of more dialogical relationships, and in an educational process characterized by hierarchical procedures, more evidently seen in the interaction between teacher and student, we raised the following question: is it possible to establish dialogical relationships in monological spaces and procedures? With the goal of finding an approximate answer to this issue, we carried out a research in a public school located in the Federal District, where we investigated the perceptions of high school adolescents on schools as spaces for dialogue, whereby personal and collective student demands are taken into consideration. For this, we chose to apply dynamic roundtable conversations between participants. The data that emerged from the students' speeches during the activity was based along the lines of Bardin (2009), who proposes a content analysis framework. The theoretical basis is scaffolded by dialogue as a pedagogical form of mediation, which is subdivided into three aspects: existential, relational and 
propositional. The results demonstrated that dialogues are absent or inefficient in this school environment, highlighting the difficulty of establishing a conversational relationship between teachers and students, due to caring restrictions and, most notably, due to the lack of importance given to pedagogical mediation as a way to favor an educational environment that is more dialogical in its educational process.

Keywords: Dialogue. Pedagogical mediation. Students. School.

Resumen: En un contexto social delimitado por contactos, principalmente tecnológicos, a expensas de relaciones más dialógicas, y en un proceso educativo caracterizado por procedimientos jerárquicos, más evidenciados en la interacción entre profesor y alumno, se planteó la siguiente pregunta: ¿Es posible establecer relaciones dialógicas en espacios y procesos monológicos? Para buscar una respuesta aproximada a este problema, se realizó una investigación en una escuela pública en el Distrito Federal, que investigó las percepciones de los adolescentes de la escuela secundaria sobre la escuela como un espacio de diálogo, considerando las demandas personales o colectivas de los estudiantes. Para esto, se eligió la dinámica de las ruedas de conversación entre los participantes. El análisis de los datos que surgieron de los discursos de los estudiantes durante la actividad se propuso siguiendo los moldes de Bardin (2009), que sugiere el análisis de contenido. La fundamentación teórica se basa en la comprensión del diálogo como mediación pedagógica, subdividida en tres aspectos: existencial, relacional y proposicional. Los resultados mostraron que el diálogo está ausente o es ineficiente en este entorno escolar, destacando la dificultad de establecer una relación dialógica entre el profesor y el alumno, debido a la restricción de la acogida y notablemente la poca importancia dada a la mediación pedagógica para favorecer un entorno más dialógico en el proceso educativo.

Palabras clave: Diálogo. Mediación pedagógica. Estudiantes. Escuela.

\section{INTRODUÇÃO}

O diálogo é um aspecto inerente à condição humana e, por isso, contribui para a formação do próprio ser humano e de sua historicidade. Mas é também uma mediação inter-humana que possibilita uma diversidade de encontros e relações. É sob esse aspecto que o diálogo será compreendido, bem como, direcionado para o espaço escolar, no qual ele poderá ser exercitado como uma mediação pedagógica, contribuindo para a superação de um contexto demarcado, principalmente, pela indiferença pessoal e pela discriminação social.

Nesse sentido, considerando que o diálogo é uma conversa com o cotidiano, é oportuno definir alguns aspectos que são problemáticos para o exercício dialogal no contexto contemporâneo. Assim, em uma percepção mais global das dinâmicas culturais, é possível depreender que o processo de desigualdade social está se acentuando continuamente. Portanto, como dialogar com sistemas que geram uma distância cada vez maior entre os poucos ricos e os muitos pobres?

Outra característica que está se revelando com uma nitidez, cada vez mais evidenciada, é a expressão das minorias sociais e culturais que, por um lado são discriminadas e, por outro, começam a se manifestar com as suas vozes e com as suas expressões culturais para reivindicar o direito que lhes deve ser atribuído e para que possam ser considerados 
cidadãos de uma sociedade que Ihes garanta dignidade humana. Com base nesse enunciado, como dialogar com as diversidades culturais e sociais?

E em um ambiente bastante expressivo, como o deflagrado nos últimos tempos, encontra-se, também, a polarização ideológica. Embora os debates ideológicos sejam extremamente saudáveis, no contexto atual, isso está se tornando uma trincheira armada para defender, apenas, interesses ou pontos de vista e opções partidárias. A polarização se tornou extremamente arraigada na cultura contemporânea, a ponto de tudo e todos serem reconhecidos como inimigos. Como estabelecer um diálogo entre processos ideológicos polarizados?

Tais questionamentos, dentre tantos outros, poderiam estar vinculados ao desejo de que o diálogo pudesse ultrapassar os dogmatismos religiosos, as facções políticas, ou os impérios econômicos. Mas, ao mesmo tempo, o diálogo está sempre em busca da verdade, por meio do reconhecimento do seu interlocutor, a fim de expressar a sua responsabilidade para com o processo de humanização, e constitui-se, também, em uma mediação para a construção de um projeto mais democrático e de uma cultura mais solidária.

Simultaneamente, o diálogo é capaz de destituir discursos ideológicos polarizados e propor estratégias de respeito e de responsabilidade pelo outro. Há ainda muitas condições para superar os doutrinamentos religiosos e exercitar o diálogo inter-religioso para buscar a fraternidade e a paz. E, enfim, possui capacidade de interagir com os sistemas de acumulação do capital para garantir uma sociedade mais saudável e sustentável. O diálogo é indicado, portanto, para superar a polarização ideológica, a doutrinação religiosa e a acumulação financeira, aspectos que são dominantes no contexto contemporâneo.

Em um olhar panorâmico desse cenário, o diálogo poderia ser entendido sob diversos aspectos, mas este será compreendido como um processo de interioridade, porque estabelece uma relação consigo mesmo; mas também de reciprocidade, pelo fato de proporcionar uma vinculação com o outro; e, de responsabilidade, por potencializar uma conexão com as possibilidades de superação das diversas problemáticas enfrentadas pelos sujeitos envolvidos. Logo, o diálogo está sendo proposto como uma dinâmica de interioridade, de reciprocidade e de responsabilidade.

Tais aspectos configuram-se, neste artigo, como elementos definidores do diálogo, com o objetivo de caracterizar-se como uma mediação pedagógica, compreendendo a dinâmica existencial de interioridade, relacional de reciprocidade e proposicional de responsabilidade. Essas categorias serão descritas na sequência.

\section{O DIÁLOGO COMO MEDIAÇÃO EXISTENCIAL DE INTERIORIDADE}

O diálogo, como uma mediação existencial, naquilo que se refere à interioridade da própria condição humana, precisa considerar as características essenciais do ser humano, que é a sua cordialidade, a inteligibilidade e o seu comportamento. Nesse sentido, quando 
se menciona a característica da interioridade, estar-se-iam revelando as distintas categorias que compõem a essência de todo o ser humano, que são o espírito, a mente e o corpo.

Sob o contexto dessas categorias, a experiência humana é demarcada, respectivamente, pela dinâmica espiritual, racional e atitudinal. Isto é, em uma realidade assentada sobre o excesso de materialidade, o homem e a mulher contemporâneos necessitam recuperar a sua energia espiritual. Da mesma forma, em um período definido pela expressiva manifestação do racionalismo instrumental, é recomendado desenvolver um pensamento mais holístico. E em um contexto fortemente delimitado pelo ativismo frenético, é aconseIhado um comportamento mais integrado aos movimentos cósmicos.

Assim, essa característica tridimensional, articulando-se o espiritual, racional e atitudinal, quando em diálogo, contribui para o procedimento educativo, e isso pode ser percebido no projeto escolar porque o processo dialogal tem uma energia educadora e, por isso, contribui com o sentido existencial. Com base nessa proposição, pode-se afirmar que o diálogo ajuda a ser mais, a pensar melhor e a agir com mais sentido, indicando a relevância dessa trilogia dialógica.

Essas categorias existenciais podem, no entanto, ser explicitadas de distintas maneiras, mas a linguagem tornou-se a mediação privilegiada desse procedimento. Assim, com o propósito de definir o diálogo como uma característica existencial, é consentâneo recuperar a experiência original dos semitas, que priorizavam a escuta dos outros; dos gregos, que defendiam ser a visão o sentido mais importante; e, dos cristãos que afirmavam ser a palavra a razão da sua experiência de fé. Enfim, estes três sentidos: o ouvir, o olhar e o falar, com base nas culturas citadas, podem se constituir em uma plataforma para edificar um autêntico procedimento para viabilizar uma cultura do diálogo.

Nesse entendimento, a escuta, a visão e a palavra, também quando em diálogo, propiciam um percurso educativo pleno de significados. Porém, em uma sociedade extremamente falante e visual, é recomendado destacar, inicialmente, o sentido da escuta. Segundo Campos, "Escutar é ter uma atitude pessoal, livre, de sintonia com o que a outra pessoa me diz, como o diz e quanto deixa transparecer no que silencia. A escuta não é um dom, mas uma aprendizagem com esforço" (CAMPOS, 2008, p. 152). Quer dizer, não se trata de uma priorização, mas de um posicionamento privilegiado que a realidade atual estaria exigindo, isto é, um exercício constante e contínuo de escuta de si mesmo, dos outros, da natureza e da divindade.

Concomitante à escuta vem a palavra que, prioritariamente, é uma vinculação que se estabelece frente a frente, embora se possa estar fisicamente distante. Mas, nessa disposição, é recomendado acolher a sugestão de que as palavras estão sempre revestidas de intencionalidades, de tonalidades e de expressividade e, sob essas perspectivas, a palavra pode ser, segundo argumentação de Freire (2005), partilhada, refletida ou pronunciada. Tais categorias, para manifestar a importância da palavra, são elementos essenciais para propor e desenvolver um diálogo.

A mediação é feita, ainda, por meio do sentido da visão. Os filósofos clássicos e, de modo mais diretivo Aristóteles (384-322 a.C.), acreditava que a visão é o órgão humano mais importante 
para se estabelecer uma relação com a realidade: "Nada está no intelecto sem antes ter passado pelos sentidos", afirmava o filósofo. Por essa razão, a visão pode se constituir como uma metáfora, porque por meio dela se abre uma brecha para compreender os problemas humanos, proporcionando um olhar para além daquilo que está sendo apresentado. Desse modo, a metáfora da visão atravessa o problema e percebe o que está para além daquilo que é perceptível.

O diálogo, revelado pelos sentidos e descrito como uma mediação existencial, caracteriza-se, segundo Buber (2009), como um processo dialógico. Segundo o autor, a dinâmica dialógica não corresponde apenas a um relacionamento entre os humanos, mas muito mais a um comportamento, cujas atitudes levam a uma reciprocidade de uma ação interior. Nessa via, a dinâmica existencial, como um processo dialógico, exige uma experiência de interioridade, que não se caracteriza pela relação com um objeto interior, mas com um sujeito que vive, na sua interioridade, uma relação consigo mesmo e com os outros.

Ao se tratar, à vista disso, o diálogo como uma relação existencial de interioridade, estar-se-ia propondo que, a partir da relação com o outro, o sujeito toma consciência da sua própria condição humana. Por conseguinte, o Eu somente se caracteriza como sujeito da sua existência, quando em relação com o Outro, que nesse caso pode se dar de distintas maneiras, mas aqui está se propondo que o diálogo pode se caracterizar, justamente, como uma dinâmica de interioridade, principalmente quando a subjetividade e a alteridade estejam em uma interação dialógica.

Enfim, em um procedimento pedagógico que considera o diálogo como uma mediação existencial, é recomendado que o processo educacional tenha por objetivo inicial potencializar as aprendizagens internas, fato que caracteriza a própria etimologia da educação, isto é, extraído de dentro. Isto é, a partir da manifestação de interioridade, por meio da escuta, da palavra e da visão, pode-se estabelecer um diálogo educativo com a diversidade de manifestações pessoais e sociais, que exigem, por sua vez, uma mediação relacional de reciprocidade.

\section{O DIÁLOGO COMO MEDIAÇÃO RELACIONAL DE RECIPROCIDADE}

Considerando as grandes tendências do mundo contemporâneo, é perceptível que as forças dominantes estejam direcionadas para a supressão de si mesmo, para a aniquilação dos outros, e para a destruição do planeta. Tal fenômeno sempre existiu na humanidade, porém, com o fortalecimento de sistemas que proporcionam, cada vez mais, o isolamento e não o acolhimento, o egoísmo e não a solidariedade, a concentração e não a partilha, tão mais necessário se torna a retomada do diálogo como uma mediação relacional.

Para dar concretude a essa proposta, a dimensão mediadora do diálogo tem como pressuposto, na sugestão de Freire (2005), que se reconheça o inacabamento do ser humano e o seu desejo constante de ser mais e melhor e, para isso, precisa-se exercitar um amor profundo aos outros e ao mundo. Isso revela a necessidade do procedimento mediador, no sentido de garantir a humanização do próprio ser humano, por meio da condição 
essencial da existência, que é o amor. Segundo o mesmo autor, o diálogo é um mediador privilegiado do amor e o amor é a forma mais adequada para o diálogo.

Outra característica para potencializar o diálogo, como uma mediação relacional, é a fé na humanidade. Conforme Freire (2005), esta fé no ser humano é entendida como uma pré-condição para estabelecer um diálogo, que não pode ser ingênua, mas crítica e construtiva. Essas características propiciam uma confiança no ser humano, principalmente nas relações com os outros. Em uma analogia ao pensamento anterior, o diálogo é um excelente mediador da fé e esta pode potencializar o diálogo.

Na complementariedade do entendimento do diálogo, como uma mediação relacional, amparado na tríade dos valores cristãos da fé, esperança e caridade, é oportuno compreender a esperança, segundo Freire (2005), como um imperativo existencial e histórico. Tal argumento aponta para a realidade do cotidiano - tanto das pessoas na sua individualidade, como, principalmente, na sua sociabilidade -, porque, por meio dela, busca-se construir a utopia necessária, ou, na linguagem freireana, procura-se concretizar o inédito viável. Assim, o diálogo é uma força desencadeadora da esperança e essa, por sua vez, é uma energia propiciadora do diálogo.

Esses três valores, do amor, da fé e da esperança, ao estabelecerem uma mediação dialógica entre si, poderiam contribuir com um processo histórico mais humanizado e, ao proporcionarem uma mediação dialógica com os outros, seriam capazes de se tornar energias desencadeadoras - segundo sugestão de Leonardo Boff no prefácio da obra Pedagogia da Esperança (Freire, 2005) - para a construção de um futuro eticamente mais justo, politicamente mais democrático, esteticamente mais irradiante e espiritualmente mais humanizador.

Nessa dinâmica relacional, pautada no amor, na fé e na esperança, desencadeia-se um procedimento de reciprocidade. Isto é, esses valores, na medida em que estiverem potencializando o diálogo, este pode caracterizar-se como uma relação de reciprocidade. Sob esse aspecto, torna-se oportuno recomendar que nas relações recíprocas o respeito pelo jeito de ser, de pensar e de agir do outro sejam considerados, tanto em dinâmicas mais próximas de amizade ou de parentesco, quanto em domínios mais públicos, como é o caso da escola ou da igreja.

Naquilo que diz respeito ao contexto educacional, é recomendado, portanto, considerar o diálogo como uma mediação relacional, por meio do amor, da fé e da esperança, porque este poderia inaugurar novas formas relacionais entre os distintos protagonistas do processo educativo, incluindo nesse procedimento os esforços das famílias, o empenho das escolas e a dedicação da comunidade local. Assim, a reciprocidade dentre os distintos sujeitos da educação e os diversos segmentos sociais poderia proporcionar uma educação mais respeitável e mais respeitosa, e, para potencializar tal projeto, precisar-se-ia contar, ainda, com o diálogo como mediação proposicional de responsabilidade.

\section{O DIÁLOGO COMO MEDIAÇÃO PROPOSICIONAL DE RESPONSABILIDADE}

O diálogo, tendo como categorias essenciais da conduta humana a mediação existencial e relacional, é impulsionado a se expressar pela autenticidade, pela ética e pela 
justiça, como manifestações de sua responsabilidade. Ou seja, todo processo dialogal está imbricado de procedimentos que buscam promover relações pessoais e sociais, em vista de um propósito que aponta para a realidade do bem viver e do bem conviver.

Tendo como referência esse procedimento, o diálogo constitui-se uma dinâmica vital e, na proposta de Souza, "viver é, antes de tudo, encontrar Outros, outros variados, com outras linguagens, outros sentidos, outras realidades: outros mundos, outras vidas" (2008, p. 10). Sendo assim, a alteridade é um elemento essencial do diálogo, porque privilegia a primazia e o protagonismo do Outro, daí a necessidade da acolhida e do cuidado nas mediações proposicionais de responsabilidade.

Nessa perspectiva, novas oportunidades de diálogo se efetivam e novas mediações são construídas. Segundo Souza, "o que é realmente importante é que as múltiplas linguagens não permaneçam estanques, isoladas em si mesmas, presas as suas próprias verdades, mas que se disponham a dialogar com outras dimensões da realidade" (2008, p. 21). Com esse objetivo dialógico, a mediação propositiva da responsabilidade poderia enumerar distintas propostas, mas, no arcabouço desta reflexão, inicialmente é indicada a autenticidade.

A autenticidade seria a primeira virtude, dentre outras, que poderiam constituir uma proposta para se desenvolver o diálogo como uma mediação propositiva. Isso demanda, no entanto, um autoconhecimento profundo, bem como, um discernimento ampliado para que os distintos comportamentos dialógicos possam ser considerados profícuos e confiáveis. Taylor (2009), na sua compreensão sobre a ética da autenticidade, invoca, justamente, a necessidade de o sujeito ser autêntico e atuar, também, de forma autêntica. Isto é, o ser e o agir precisam estar, de forma concomitante, interagindo para proporcionar um diálogo responsável.

Como desdobramento dessa categoria da autenticidade, estar-se-ia propondo uma segunda virtude, que seria a exigência ética, isto é, na dinâmica intersubjetiva do diálogo exige-se, sempre, um princípio ético. A partir da autoconsciência, que na vinculação com uma consciência relacional, pode-se afirmar e confirmar uma consciência comunitária, pelo conhecimento e reconhecimento do outro, considerado um ambiente propício para vivenciar o diálogo como um procedimento baseado na experiência ética.

O diálogo tem, ainda, como pressuposto dessa mediação, um princípio de justiça. Essa seria outra característica do diálogo o qual poderia modelar um esquema que, segundo Gadamer, "quando bem empregado, torna-se muito fecundo: no intercâmbio das forças e no confronto dos pontos de vista vai se construindo uma comunidade que ultrapassa o indivíduo e o grupo ao qual pertence" (GADAMER, 2002, p. 321). Justamente por ser um princípio universal, a justiça como expressão do diálogo imprime um caráter de responsabilidade para com a diversidade cultural e para com a multiculturalidade social.

Por essa razão, a teoria da justiça proposta por Rawls (2000) tem como princípio a igualdade e a liberdade, visando à construção de uma sociedade justa e equitativa. Ser equitativo, para o autor, é caracterizar a todos com as mesmas oportunidades, em vista da 
edificação de uma sociedade democrática. Isto é, para que todas as pessoas sejam tratadas de forma justa, é necessário estabelecer sistemas sociais que desempenhem suas funções com justiça.

A mediação como responsabilidade, dentre tantos outros argumentos, está sendo proposta com base na autenticidade, na ética e na justiça. São esses valores que podem configurar um diálogo pautado na responsabilidade, quando o "eu" responde de forma autêntica, ética e justa pelo bem viver de cada ser humano e pelo bem conviver de todos com o universo.

Porém, na experiência da cultura moderna, principalmente naqueles aspectos que tratam da abordagem mais pedagógica, não é possível um procedimento dogmático, mas se exige, cada vez mais, um diálogo que acolha outras experiências e, em um processo de correlação de iniciativas metodológicas, é recomendado conduzir um percurso de ensino e aprendizagem, progressivamente mais interativo e integrador com o diferente, com o diverso e com o distinto.

Dado isso, a partir dos debates oriundos das rodas de conversa que tiveram como tema-gerador a "escola como espaço de diálogo", tentou-se buscar as percepções dos participantes quanto às principais demandas estudantis, sejam elas pessoais ou coletivas, no contexto escolar.

\section{CAMINHOS METODOLÓGICOS PERCORRIDOS}

Após compreender o diálogo como uma mediação existencial de interioridade, relacional de reciprocidade e proposicional de responsabilidade, buscamos perceber como essa realidade é vivenciada no espaço escolar e entre os sujeitos da educação. Para isso, a pesquisa exploratória teve como sujeitos estudantes do ensino médio de uma escola da rede pública do Distrito Federal, realizada com seis turmas do $2^{\circ}$ ano, compondo um quadro de 74 participantes (8 estudantes da turma A; 18 da turma B; 15 da turma C; 9 da turma D; 11 da turma E e 13 da turma F), na faixa etária de 15 a 17 anos.

Optamos por uma metodologia participativa, no intuito de favorecer uma prática dialogada que estivesse alinhada aos objetivos da pesquisa. Para isso, elegemos a dinâmica das "rodas de conversa" entre os participantes. Segundo Afonso e Abade, essas rodas devem "motivar e potencializar esses interesses iniciais para ampliar os horizontes dos educandos, problematizando as questões colocadas e indicando novos desafios para o conhecimento e a reflexão" (2008, p. 11). Além do estímulo à participação dos estudantes, a roda de conversa deve considerar a especificidade do grupo ao eleger temas para serem abordados.

Nesta pesquisa, as rodas de conversa foram realizadas durante as aulas de Artes, já que houve receptividade do professor para aplicação dessa metodologia em sua disciplina. Antes de iniciarmos as rodas de conversa, planejamos como elas seriam aplicadas, ou seja, quantas e quais turmas iriam participar da atividade, quais estratégias e materiais seriam 
empregados, a duração da atividade, os dias e horários de aplicação, a escolha do moderador, assim como a seleção do tema-gerador. A partir dessa organização, após a aceitação dos estudantes para participar das rodas, definimos que a melhor estratégia seria unirmos grupos de aproximadamente 25 estudantes formados com as 6 turmas participantes.

Divididos em três grupos, os estudantes foram convidados para conversar acerca do seguinte tema: A escola como espaço de diálogo para discussão dos assuntos que os afetam. Nesse entendimento, buscávamos conhecer as percepções dos participantes quanto às principais demandas estudantis, fossem elas pessoais ou coletivas, no contexto escolar. Para isso, dividimos o dia da roda em três momentos: a) momento inicial (preparação do grupo); b) momento intermediário (reflexão) e c) momento final (sistematização e avaliação do dia) (AFONSO, 2006).

Para Campos (2010, p. 79), "as Rodas são espaços coletivos e concretos - de lugar e tempo - destinados à comunicação - escuta e circulação de informações sobre desejos, interesses e aspectos da realidade -, à elaboração - análise da escuta e das informações - e tomada de decisão - prioridades, projetos e contratos". Tratando-se da dinâmica dessa atividade, estávamos abertos à escuta para ouvirmos vontades, sentimentos, preferências, intenções, sugestões, dentre outros pontos, deixando que a fala dos participantes fluisse sem interferência do pesquisador/moderador, isto é, não atuando como um "controlador das sessões".

Em seguida, buscamos valorizar os diferentes olhares dos participantes, separando as falas por demandas, em blocos, para realizar a análise do que emergiu dos grupos. Com o intuito de preservar o anonimato dos estudantes, os nomes ficticiamente foram nomeados por números, ao lado de letras representando a turma a que pertenciam (1A, 2A, 3A; $1 \mathrm{~B}$, 2B, 3B; 1C, 2C, 3C; e assim por diante).

Nessas análises, adotamos os estudos de Bardin (2009), que orienta sobre as fases fundamentais a serem consideradas: pré-análise, exploração do material e tratamento dos resultados. Na primeira fase, preparamos o material, transcrevendo-o e realizando o que a autora chama de 'leitura flutuante'. Em seguida, na segunda fase, utilizamos a administração de técnicas no corpo do material a fim do cumprimento sistemático de decisões tomadas anteriormente na leitura, e na terceira etapa, apoiados nos resultados que emergiram da exploração do material, buscamos torná-los significativos e válidos, realizando "correspondência entre as estruturas semânticas ou linguísticas e as estruturas psicológicas ou sociológicas (por exemplo: condutas, ideologias e atitudes) dos enunciados" (BARDIN, 2009, p. 40).

De acordo com os modos de mediação do diálogo, problematizados neste artigo, subdividimos as percepções dos jovens, a partir de três aspectos aqui considerados: a) mediação existencial, quando o diálogo se coadjuva e se estabelece na relação com os sentidos; b) mediação relacional, quando o diálogo se consuma na perspectiva de conviver com diferentes formas de ver o mundo, na diversidade das identidades e na relação com o outro; e c) mediação propositiva ou promotora de responsabilidades, quando o diálogo transforma, problematiza e pronuncia o mundo, como ilustrado no Quadro 1 a seguir. 
Quadro 1: Estrutura das rodas

\begin{tabular}{|l|l|l|}
\hline Tema-gerador & A escola como espaço de diálogo para discussão dos assuntos que os afetam \\
\hline Momentos & Objetivos/esclarecimentos & Interrogações (subtemas) \\
\hline Momento inicial & $\begin{array}{l}\text { Preparação do grupo: explicações so- } \\
\text { bre a metodologia da roda }\end{array}$ & Há diálogo? Como é construído? \\
\hline Momento intermediário & $\begin{array}{l}\text { Reflexões: trocas de experiências e } \\
\text { acolhimento }\end{array}$ & $\begin{array}{l}\text { Por que há essas ocorrências? } \\
\text { O que falta? O que é produzido? }\end{array}$ \\
\hline Momento final & $\begin{array}{l}\text { Sistematização e avaliação do dia: ne- } \\
\text { cessidades explícitas dos grupos }\end{array}$ & O que fazer? Como fazer? \\
\hline
\end{tabular}

Fonte: Adaptado pelos autores (AFONSO, 2006).

Aliado a isso, buscou-se compreender o que resultou deste espaço coletivo de fala - as rodas - como engrenagem propícia a potencializar a autonomia dos envolvidos para a mudança dos modos tradicionais de educação.

\section{O DIÁLOGO COMO MEDIAÇÃO PEDAGÓGICA}

Tendo como referência a contribuição teórica, é possível perceber na análise dos dados que um dos modos da mediação pedagógica é o diálogo existencial, que se estabelece em uma via de mão dupla na qual o diálogo é mediado pela escuta, pela palavra e pela visão. Durante a pesquisa, muitos estudantes, em tom de apelo, afirmaram a vontade de que têm de ser ouvidos acerca de ideias, assuntos e desejos, ressaltando o quanto essa necessidade é premente. Na roda de conversa, um dos estudantes, assim se expressou:

\footnotetext{
A escola como segunda casa deveria ser mais aberta à fala sobre questões vividas diariamente por alunos e funcionários, causando assim uma relação mais íntima entre o corpo docente e discente. Isso nos tornaria mais fortes para irmos atrás de melhorias para nós mesmos $(3 \mathrm{~A})$.
}

Esta manifestação revela, justamente, a importância de a escola se caracterizar como um espaço do diálogo, bem como, as vantagens deste procedimento no ambiente escolar. Quanto a isso, Freire reafirma que o diálogo se caracteriza como uma exigência existencial, fazendo eco à manifestação estudantil, principalmente na medida que considera que uma relação mais íntima (dialogada) os tornaria mais fortes e, consequentemente, promoveria melhorias. Na continuidade, o próprio autor afirma que o diálogo "é o encontro em que se solidarizam o refletir e o agir de seus sujeitos endereçados ao mundo a ser transformado e humanizado" (FREIRE, 2005, p. 45); ou seja, o diálogo promove mudanças entre aqueles que o praticam.

No contrafluxo desse depoimento encontra-se, justamente, uma expressão bastante diferente, que pode ser percebida na sequência: 
Bom, o que me afeta é justamente a falta de diálogo, a gente não tem contato um com o outro, tanto a gestão, como os alunos. Eu não me sinto parte da escola. Lembro que antes a escola era minha segunda casa, eu tinha prazer em vir para a escola, em conviver com meus colegas. Hoje não, porque o contato esfriou, a vontade acanhou e tudo se tornou mais uma obrigação (1B).

A estudante não só reclama da falta de diálogo no espaço estudantil, como também revela que hoje, nesse lugar, não há espaço para fala, há uma crise de contato e, ao mesmo tempo, associa o diálogo à satisfação de estar ou não em um lugar. Nesse sentido, depreende-se que o diálogo é também uma necessidade humana, cuja falta oprime, favorecendo o nascimento de tristezas e angústias, como as narradas.

Por sua vez, percebe-se a ausência do diálogo mediado, restando apenas a obrigação, onde nada se opera, como complementa Freire (2005, p. 45): "não se pode reduzir-se a um ato de depositar ideias de um sujeito no outro, nem tampouco tornar-se simples troca de ideias a serem consumidas pelos permutantes". Daí a relevância de compreender o diálogo como uma mediação existencial, justamente porque nessa abordagem estariam contemplados os aspectos emocionais, racionais e atitudinais.

Na sequência a essa proposta, Buber sugere que o diálogo deveria se dar no encontro (imediato e totalizante), e pelo contato da acolhida e da receptividade: "O Tu se apresenta a mim. Eu, porém, entro em uma relação imediata com ele. Assim, a relação é, ao mesmo tempo, escolher e ser escolhido, passividade e atividade" (2001, p. 102). Essa proposta revela, justamente, a necessidade de o diálogo se caracterizar como um encontro e uma relação.

Ainda nesse contexto, outras falas estudantis expuseram a necessidade de mais afetividade dos professores e gestores da escola para com os alunos. Outros, porém, enfatizaram o respeito, aspecto que pode ser percebido na manifestação seguinte:

\footnotetext{
A escola não é um lugar de todos pontos negativos, porém, eu acredito, que tenha que parar de ser um ambiente em que temos que ser obrigados a fazer algo contra nossa vontade e sem ouvir nossas opiniões. Acredito que em um lugar, que é basicamente, composto por alunos é total absurdo não escutarem o que temos para dizer. Advertências são dadas por desrespeito, sendo que o respeito é dado conforme recebido, se exigem é porque têm que praticar o mesmo com o próximo (9C).
}

Nessa narrativa, o estudante questiona a imposição de normas sem a devida oitiva dos jovens; ao mesmo tempo, nos diz que o respeito se estabelece entre o eu-tu, isto é, entre escola-alunos, indivíduos-indivíduos. Ainda de acordo com essa observação, é possível depreender que os estudantes precisam ser considerados sujeitos participantes do processo educativo, fato que poderia reforçar a percepção de um diálogo com uma característica mais existencial.

Muitas falas sugeriram o envolvimento de toda a comunidade escolar, principalmente, intramuros (estudantes, professores, coordenadores e diretores) na promoção do diálo- 
go. Em sua maioria, os relatos percebem a escola com grupos antagônicos, nos quais os estudantes representam o "grupo sem voz", como se destaca no Quadro 2:

Quadro 2: Percepções dos estudantes acerca das relações (nós versus eles)

\begin{tabular}{|l|l|}
\hline \multicolumn{1}{|c|}{ Eu/nós } & \multicolumn{1}{c|}{ Eles } \\
\hline Alunos que só escutam & $\begin{array}{l}\text { A direção funciona sem muitos problemas se 'ouvir' } \\
\text { um pouco os alunos }\end{array}$ \\
\hline Os alunos não têm voz & $\begin{array}{l}\text { Todos tratam os alunos como minoria, que não } \\
\text { manda em nada }\end{array}$ \\
\hline $\begin{array}{l}\text { Somos seres humanos e merecemos ser tratados } \\
\text { com mais atenção e carinho }\end{array}$ & Só os professores e diretores têm moral \\
\hline $\begin{array}{l}\text { Nós deveríamos nos expressar, não somente } \\
\text { aprender }\end{array}$ & Eles devem ouvir, não julgar ou ignorar \\
\hline Deveria ser um lugar para nos sentirmos bem & A escola deve tomar decisões junto com os alunos \\
\hline Deveríamos ter apoio, compreensão e segurança & A escola deveria ser mais compreensiva. \\
\hline
\end{tabular}

Fonte: Elaboração dos autores

Do lado esquerdo do quadro, descrevem-se narrativas, sintetizando as principais queixas dos estudantes. Nessas falas, além de uma demanda por manifestações de bem-estar (atenção, carinho, apoio, compreensão e segurança), houve uma queixa do grupo estudantil que se percebe sem voz, sem escuta e sem expressão, requerendo aquilo proposto como mediação existencial, que se dá pela palavra, escuta e visão. De acordo com a percepção da maioria dos participantes, o espaço escolar deveria ser um ambiente de escuta sensível e acolhimento (um lugar para nos sentirmos bem), no entanto, observou-se que o diálogo entre estudantes e demais membros da escola não tem ocorrido, principalmente pela não participação estudantil com a sua voz na instituição. Interessante ainda é perceber a distinção entre expressão e aprendizagem, na qual a expressão revela-se como uma manifestação interior, isto é, uma condição para pontencializar a aprendizagem interna.

Do lado direito do Quadro 2, por sua vez, reunimos falas que remetem a outro polo, cuja posição denota uma relação hierárquica superior, tanto na designação dos termos (eles-direção-escola) quanto nos núcleos das falas (julgar-ignorar-mandar-tomar decisões-ter moral). Nesse contexto, considerando o diálogo como uma mediação existencial, a partir das condições percebidas e/ou sentidas pelos estudantes, não foi possível inferir a presença do diálogo como condicionante para que esses jovens possam melhor pensar e agir com mais sentido. Ao mesmo tempo, o diálogo foi reconhecido, principalmente, como indispensável, urgente e inadiável condição para superar as dicotomias entre os sujeitos da escola.

Diante dessas revelações, buscou-se compreender, durante as rodas de conversa, quais assuntos/temas os estudantes desejariam ter dialogados na escola, tendo como referência a seguinte manifestação: "Seria interessante demais, uma escola que tenha discussões sobre as- 
suntos que atinjam a nossa realidade, nosso cotidiano" (12C). Essa fala nos mostra o desejo dos estudantes em participar e dialogar, principalmente sobre os assuntos que mais lhes interessam.

Esse repertório, que compõe o diálogo, na proposta de Buber (2001), concretiza-se por meio de uma relação, na qual o eu e o tu se aproximam para concretizar a comunicação, em uma dimensão singular da dinâmica comunicativa que se completa, principalmente, para aumentar a compreensão e conhecimento dos envolvidos nesse processo. Isso significa que não somente a aproximação pelos sentidos é necessária à mediação dialógica; a reciprocidade entre a transmissão dos conteúdos abordados, que ultrapassam a compreensão da linguagem e seus signos, é igualmente relevante na comunicação e, em especial, na prática educativa.

Durante as reflexões, quando os estudantes nos informaram a ausência de diálogo e espaços de discussão, percebemos, explícitas nas falas, reinvindicações por ocupação e ampliação de lugares de fala e por visibilidade no atendimento a seus saberes, experiências e interesses. Diante dessa falta, indagamos os estudantes acerca de quais tópicos gostariam de ter presentes em seu cotidiano escolar. Com isso, vários assuntos vieram à tona, como expostos no Quadro 3, destacando-se, ao lado esquerdo o tema proposto, e, ao lado direito, as falas estudantis.

\section{Quadro 3: Repertório estudantil}

\begin{tabular}{|c|c|}
\hline Tema & Falas \\
\hline Aborto & $\begin{array}{l}\text { "Esses temas discutidos de maneira aberta para haver uma comunicação } \\
\text { maior" (7F) }\end{array}$ \\
\hline Bullying & "Conviver com muitos que te rejeitam e te colocam para baixo" (7A) \\
\hline $\begin{array}{l}\text { Depressão, ansiedade, } \\
\text { saúde mental }\end{array}$ & $\begin{array}{l}\text { "Também deveria ter uma pessoa de confiança para poder ter conversas } \\
\text { sobre depressão com os alunos" (10E) } \\
\text { "Os professores tivessem um certo cuidado com o aluno que sofresse esses } \\
\text { transtornos" (9E) }\end{array}$ \\
\hline $\begin{array}{l}\text { Educação sexual, violên- } \\
\text { cia sexual/abuso sexual, } \\
\text { sexualidade e gênero }\end{array}$ & $\begin{array}{l}\text { "Assuntos como a sexualidade, o assédio e outros são quase proibidos" (1E) } \\
\text { "Acredito que na escola deveria tratar mais sobre questões de sexualidade e } \\
\text { gênero" (12C) }\end{array}$ \\
\hline Esporte & "Há falta de incentivo no esporte" (5F) \\
\hline $\begin{array}{l}\text { Gravidez na adolescência } \\
\text { Gravidez precoce }\end{array}$ & $\begin{array}{l}\text { "Seria um lugar bem mais hospedeiro, um lugar onde pudéssemos falar } \\
\text { sobre..." (2D) } \\
\text { Alguns assuntos para a discussão poderiam ser gravidez precoce, racismo e } \\
\text { homofobia" (1D) }\end{array}$ \\
\hline Homofobia & "Acho que deveria ter um apoio para quem é LGBT" (1C) \\
\hline Racismo & "Em toda escola que eu vejo tem tanto racismo como homofobia" (3E) \\
\hline Sociedade e política & $\begin{array}{l}\text { "Precisa de orientação para viver em sociedade porque o psicológico ainda } \\
\text { não é } 100 \% \text { " (2F) }\end{array}$ \\
\hline Uso de drogas & $\begin{array}{l}\text { "A escola deveria abordar mais o assunto das drogas" (3D) } \\
\text { "A escola deveria debater sobre drogas para que haja uma conscientização" } \\
(2 E)\end{array}$ \\
\hline
\end{tabular}

Fonte: Elaboração dos autores 
Quanto à frequência com que os assuntos foram apontados, destacaram-se: racismo, homofobia, sexualidade, gênero e saúde mental, quase sempre seguidos de exemplos de como essas questões afetam o cotidiano escolar. Vale ressaltar pesquisas que identificaram a necessidade de discussões sobre temas como os citados pelos estudantes, principalmente, no combate a tratamentos discriminatórios na escola (CAVALLEIRO, 2001; BENTO, 2006; ABRAMOVAY, CUNHA e CALAF, 2009). Estas últimas pesquisadoras investigaram sobre violência e convivência em escolas no Distrito Federal e, no tocante à discriminação, constataram um quadro de violência entre jovens: "[...] Os tipos mais informados foram a homofobia, com $63,1 \%$ das respostas dos alunos e $56,5 \%$ dos professores, e o racismo, com 55,7\% dos alunos e 41,2 \% dos professores" (ABRAMOVAY, CUNHA e CALAF, 2009, p. 11).

Gomes (2006, p. 28) ainda destaca que:

A luta contra toda e qualquer forma de naturalização e estigmatização das diferenças tornou-se um dever da humanidade, pois as experiências humanas já vividas e a que assistimos nesse início de século XXI têm-nos revelado que a intolerância, o racismo e a discriminação, ou seja, formas negativas de lidar com as diferenças, poderão nos levar a intensos processos de desumanização.

Parece-nos que as falas apresentadas no Quadro 3 confirmam esses processos de desumanização, que nos traz Gomes, pois muitas dessas salientam principalmente sentimentos negativos, como rejeição e depressão, aliado à necessidade de confiança, apoio e cuidado por meio de orientação. Ao mesmo tempo, ressaltam a proibição, na contramão do argumento da autora, e propõem uma melhor comunicação e debates na escola para a conscientização dos estudantes. Citem-se, ainda, que estudos sobre discursos ideológicos em livros e materiais didáticos como promotores de desigualdades raciais, sexuais e de gênero têm fomentado o debate para desconstruir preconceitos e outras formas de intolerância nas escolas (PINTO, 1987; ROSEMBERG, BAZILLI e SILVA, 2003; SILVA, 2008).

Nesse sentido, temas como homofobia, sexualidade e gênero se constituem importantes para o diálogo com a juventude, para que essa compreenda e valorize as diferenças no ambiente escolar, como opinam os estudantes:

A escola deveria tratar assuntos que hoje estão muito abrangentes, trazer diálogos sobre o racismo e sobre a homofobia que muita gente sofre e tem medo de falar. Diálogos assim ajudam muito as pessoas que sofrem (3E).

Existe um grande tabu para certos assuntos que contrapõe essa situação. Por exemplo: funcionários e professores evitam o diálogo sobre sexualidade (orientação sexual) das pessoas. É um caso muito importante, principalmente, na adolescência, quando os jovens estão tentando se entender. Porém, os professores, principalmente, são orientados a não falar sobre isso e advertidos se falarem (8B). 
Percebe-se que os grupos pesquisados desejam ter voz no ambiente educativo e sabem se posicionar e dizer sobre quais conteúdos gostaria de dialogar. O diálogo é, portanto, para o estudante meio para ajudar e transformar; assim deve ser compreendido como indutor de resistência, no fortalecimento das identidades, porque quando alguém age diferente do que é esperado, quanto ao comportamento, tende a sofrer discriminação, intimidação ou até violência. Os temas, conforme sugerem os estudantes, podem contribuir para uma relação social menos desigual, sem medo, sobretudo quando o jovem passa a entender sobre si e sobre o outro, superando tabus e estereótipos sociais. Estes capazes de demarcar relações hierarquizadas, desumanizando e discriminando os estudantes, impondo-lhes um estigma, individual ou coletivamente (GOFFMAN, 2004).

Em outra perspectiva, dada a importância do tema, o estudante denuncia a presença de tabus e até mesmo orientação para que o assunto não seja exposto com os estudantes ("os professores, principalmente, são orientados a não falar sobre isso e advertidos se falarem"). Nesse fato, concretiza-se o afastamento entre os atores envolvidos no processo educativo quando o diálogo mediado pelas relações se exaure pela quebra do pacto pedagógico.

Ora, se é indicado compreender o diálogo, na mediação relacional, por meio do amor, da fé e da esperança, como se pode estruturar esses valores em um espaço que opta por formulações tradicionais apoiadas no não reconhecimento das necessidades dos destinatários à prática educativa? Em Freire (2011), verifica-se a necessidade de se construir um novo olhar sobre a educação. Com ele, percebe-se a importância do amor nas relações pedagógicas, capaz de transformar a vida; a importância da troca, do coletivo, da parceria em educação, do compartilhar com o outro: o diálogo, a palavra, o encontro e reencontro, o pensar autêntico, o respeito ao indivíduo, às suas diferenças e à cultura de cada um.

Além desta abordagem, os estudantes se reportaram, ainda, ao tema da saúde mental, assim se expressando:

A escola deveria ser um lugar acolhedor, seguro e que buscasse uma relação mais próxima com o aluno, que procurasse e se preocupasse com a saúde mental do estudante. A depressão, a ansiedade, entre outras doenças mentais estão cada vez mais frequentes entre os jovens (J1).

Um assunto bem delicado, porém, é um assunto onde deve ser abordado é a depressão. [...] O quanto é difícil desabafar, as consequências, o comportamento na sociedade. As pessoas sempre acham que uma pessoa depressiva quer acabar com isso se suicidando, por isso deveria ter um conhecimento maior, conhecer as pessoas com essa doença ( $G$ 2).

Nesses relatos, é perceptível uma tensão posta entre os conteúdos estabelecidos e os requeridos. A escola acolhedora e segura, esperada na fala, dá lugar a um local distante, limitado e insuficiente, contrapondo-se a um espaço próximo, pretendido e distenso. Mais uma vez, depreende-se um apelo para uma escuta mais atenta às necessidades estudan- 
tis, pela qual o exercício do diálogo seria o caminho para o enfrentamento de conflitos, ao mesmo tempo, fortalecimento individual e coletivo, e, consequentemente, para uma escola promotora de responsabilidades.

Busca-se, ainda, compreender o diálogo como mediação proposicional, ou seja, um diálogo capaz de promover responsabilidades, quando o diálogo transforma, problematiza e pronuncia o mundo. Na escola, a formação de cidadãos emerge como uma possível orientação dessa transformação.

Dando continuidade às conversas dos estudantes, percebe-se que eles têm ciência do papel do diálogo transformador:

Por muitos anos, as escolas vêm nos submetendo a um sistema monótono de educação, onde professores se dão como superiores daqueles que deveriam ser o 'futuro do país' (3D).

Essa visão compreende a educação como um sistema hierárquico opressor e monótono, no qual o estudante não tem vez; no entanto, entendem também que a educação se faz por meio do debate, do aprendizado e da descoberta, ou seja, um diálogo capaz de provocar mudanças. Discutindo a dimensão ideológica do que é ensinado em sala de aula, Gadotti (2001, p. 73) propõe:

Uma pedagogia transformadora que não atua apenas ao nível da ideologia, da teoria. Visa especialmente à formação de grupos políticos preocupados em defender as relações humanas, a qualidade das relações que se estabelecem na escola e que determinarão a qualidade do que é ensinado.

Para o autor, a escola pode alavancar muitas discussões, porque o que é ensinado nela pode contribuir para mudanças individuais e sociais, já que a escola é um espaço onde as ideias são discutidas. Para referendar essa proposta, uma estudante apresenta a seguinte manifestação: "Se não questionarmos, não comentarmos e não tivermos o poder de interferir no que nos afeta, aonde mais faremos?" (10B). Com base nessa proposta, a escola deveria exercer um papel fundamental em sua formação, sendo um local estratégico para o exercício do diálogo.

Muitas percepções problematizaram o modelo de ensino como ultrapassado e autoritário, aspectos que podem ser percebidos nas seguintes manifestações:

A escola deveria ser um bom lugar, eles tentam passar a ideia que é um bom lugar. Mas, na verdade, esse local não é bom. Um ensino que funcionava 300 anos atrás. Atrasado. Tudo no mundo evoluindo, menos o sistema de ensino feito para fazer máquinas automáticas: _Sentem-se', eles dizem. 'Calem-se', eles dizem. 'Vocês não serão nada sem isso', eles dizem. Sério? Já é 2019 e a gente ainda tá nisso? Não precisamos mais de máquinas (7F). 
Queremos uma escola que nos eduque, não que nos reprimissem como ainda está sendo. Os alunos que frequentam muitas vezes não são ouvidos pelos coordenadores da escola. O melhor ambiente para se ensinar e aprender são lugares confortáveis para professores e alunos, não lugares de repressão. (13C).

Nessas falas, mais uma vez, os apelos dirigem-se à palavra e à escuta. Uma e outra, ambas necessárias no processo educativo, no contexto de um processo dialógico. Para Freire, ensinar exige saber escutar e disponibilidade para o diálogo, porque a escuta é democrática e o cidadão se forma pela comunicação. Segundo Freire,

Uma das tarefas essenciais da escola, como centro de produção sistemática de conhecimento, é trabalhar criticamente inteligibilidade das coisas e dos fatos e a sua comunicabilidade. É imprescindível, portanto, que a escola instigue constantemente a curiosidade do educando em vez de "amaciá-la" ou "domesticá-la". É preciso mostrar ao educando que o uso ingênuo da curiosidade altera a sua capacidade de achar e obstaculiza a exatidão do achado. É preciso por outro lado e, sobretudo, que o educando vá assumindo o papel de sujeito da produção de sua inteligência do mundo e não apenas o de recebedor da que lhe seja transferida pelo professor (2011, p. 26).

Vale ressaltar, ainda, a fala de uma estudante que salienta: "Dialogar não é uma habilidade adquirida, é construída a longo prazo" (3B). Com esta manifestação, o estudante está indicando que o diálogo é construído cotidianamente no fazer contínuo, cujas considerações sobre essa prática serão debatidas a seguir.

\section{O DIÁLOGO COMO PRÁTICA PEDAGÓGICA}

Durante as rodas com os estudantes, percebemos o quanto entendem, embora ainda adolescentes, sobre a relação entre escola e diálogo. Seus relatos indicaram o quanto o diálogo está ausente ou é ineficiente no ambiente escolar. Isso pode ser percebido pela dificuldade em se estabelecer uma relação dialogal entre professor e aluno, pela restrição de acolhida e pelo desrespeito à diversidade cultural no ambiente escolar, bem como, pela insignificância da mediação dos conflitos para potencializar um ambiente mais dialógico no processo educativo. À luz dessas considerações, busca-se analisar esses entraves que impedem que o diálogo se concretize na prática pedagógica escolar.

O primeiro obstáculo justifica-se pela tendência à manutenção de práticas tradicionais de ensino ao longo da história da educação no Brasil, nas quais o estudante é tratado como sujeito passivo no processo educativo. Note-se, no entanto, que a Secretaria de Educação do Distrito Federal (SEDF), na construção do documento norteador do currículo para educação básica adotou a Teoria Crítica e Teoria Pós-crítica, com amparo na Pedagogia Histórico-Crítica e na Psicologia Histórico-Cultural: 
O movimento deste Currículo é político, pedagógico, flexível, transformador, crítico, reflexivo, diverso, libertador de correntes, sejam ideológicas, científicas, filosóficas. O movimento é vida, é verdade prenhe de realidade, é senso comum e ciência, é relação teoria e prática, é elemento de poder. Poder como possibilidade de constituição da práxis transformadora da realidade social (DISTRITO FEDERAL, 2016, p.79).

Nesse enunciado, há nitidamente uma divergência entre o conjunto de intenções políticas e a prática no ambiente escolar, como observado. Sendo assim, como se explicam tais distorções?

Para Arroyo (2014), a história civilizatória, em especial da América Latina, vivenciou, da colonização à pós-colonização, processos de opressões e resistências que tiveram seus reflexos nas pedagogias. Essas tensões ainda hoje estão presentes nas relações institucionais educativas e entre os atores sociais que participam dessas. Às pedagogias e atores, que resistem às relações desiguais, à dominação e à subalternidade, o autor chamou de 'outras pedagogias' e 'outros sujeitos'.

Em tal cenário, Arroyo nos demonstra que esses outros sujeitos lutam por tornarem-se presentes, recusando-se à passividade e submissão, e, por isso: a) reagem ao silenciamento; b) contestam o lugar inferior em que são colocados; c) não se reconhecem no lugar onde estão segregados, d) não se reconhecem marginais; e) não se reconhecem excluídos; f) não se reconhecem desiguais; e g) se mostram conscientes e politizados. Ou seja, esses sujeitos têm voz, vez e saberes: "A pedagogia escolar sintetiza essa exclusividade rígida do pensamento pedagógico, onde os impensáveis outros saberes e Outras Pedagogas vindas, sobretudo, dos setores desescolarizados ou próprias de seres decretados inferiores" (ARROYO, 2014, p. 33).

Retomando-se às falas dos estudantes, a dificuldade em se principiar uma relação dialogal na prática pedagógica está ancorada na convicção de que esses jovens vêm em busca de conhecimento, para ocupar o latifúndio do saber, dispostos a ceder a suas vivências e leituras de mundo. No entanto, os coletivos juvenis se manifestam, põem em evidência os seus questionamentos e se afirmam como sujeitos, conforme expressa a seguinte fala: "Em todas as lutas por direitos, os grupos tiveram espaço de fala (mesmo os que tiveram que lutar por ele). Por que isso não acontece na escola? (2E)".

Com essa pergunta, traz-se para a discussão o segundo entrave: restrição de acoIhida e desrespeito à diversidade cultural no ambiente escolar. Arroyo (2014, p. 140) afirma: "Há um processo seletivo no reconhecer as diferenças. Há intenções políticas de reconhecer uns coletivos e não outros, umas lutas e não outras". Ora, isso também tem reflexo na prática pedagógica, pois, do mesmo modo que o Estado, ao elaborar políticas, faz escolhas, a escola também as faz e os estudantes sabem disso: "Devemos debater e aprender sobre coisas básicas que nos ajudem a saber quem somos e quem queremos ser (3D)". Para esse estudante, saber o que "nós" somos, significa querer ter autonomia sobre si, sobre esse eu que se afirma e representa um conjunto de identidades, individual e coletivamente. 
De acordo com Teodoro (1987, p. 46):

A soma das identidades individuais, dentro de um contexto determinado, forma a identidade cultural de um grupo étnico ou de uma sociedade, que se transmite pela cultura, pelo ensino, pela educação. Daí a necessidade do sistema educacional levar em conta as diversidades que compõem uma mesma cultura a fim de não criar problemas de ordem psíquica nos educandos.

Portanto, esse sistema educacional não pode ignorar essas vozes que não admitem mais o silenciamento e os vários modos de não reconhecimento (étnico, racial, de gênero, território, classe e outros), por isso, sobretudo resistem a práticas pedagógicas que não Ihes dê a devida acolhida e compreenda-os como conscientes e politizados, prontos a intervir e pensar conjuntamente a prática educativa.

Por fim, a insignificância dada à mediação dos conflitos para potencializar um ambiente mais dialógico no processo educativo é também um entrave que impossibilita que a escola se torne um espaço mais humano - construído por coletivos de dentro e de fora, sem impedimentos de passagem. Assim, propõe-se a necessidade de se disponibilizar espaços compatíveis para o exercício do diálogo, seja nas relações mais pessoais, bem como, nas mediações pedagógicas, objetivando fortalecer processos mais interativos e responsáveis, dentre os distintos protagonistas no campo educacional, e dinâmicas mais dialógicas entre procedimentos de ensino e aprendizagem.

Diante de tais desafios, considerando que o diálogo é um elemento inerente à condição humana, pode potencializar a razão de viver e conviver, seja consigo mesmo, com os outros, com a natureza e com o transcendente. Mas é, também, uma mediação para estabelecer condutas mais transparentes entre os diversos sujeitos envolvidos em um processo de formação pessoal e social, como é o caso dos espaços educativos.

Cabe-nos agora, na continuidade da pesquisa, darmos os encaminhamentos necessários aos gestores sobre suas percepções da escola e sobre os temas solicitados pelos estudantes a serem inseridos na prática educativa.

\section{CONSIDERAÇÕES FINAIS}

Iniciamos o artigo questionando como dialogar com sistemas, que geram uma distância cada vez maior entre os poucos ricos e os muitos pobres e com as diversidades culturais e sociais, bem como estabelecer um diálogo entre processos ideológicos polarizados. No contexto desse cenário maior, introduzimos uma questão mais específica para o contexto escolar: É possível estabelecer relações dialógicas em espaços e processos monológicos? Tais questionamentos fazem parte de uma só engrenagem, no entanto, cada roda continua girando em torno do seu eixo. As dicotomias persistem e, provavelmente, continuarão a produzir processos cada vez mais polarizados, enquanto as diferenças con- 
tinuarem amparadas pelo discurso da igualdade, tão presente nas formulações políticas, sociais e pedagógicas.

Por sua vez, a diversidade cultural e social faz parte do existir de todos, compõe nossa engrenagem, por isso, é tarefa também da escola e dos educadores lidarem com a heterogeneidade no cotidiano escolar, que se dá na relação com o outro e encontra no diálogo sua forma mais autêntica de partilha. Os estudantes da escola pesquisada nos deram muitos indícios e contribuições significativas sobre como essas aproximações podem ser construídas pelo movimento da roda.

Para isso, retomamos as formas do diálogo como mediação pedagógica e suas implicações na escola como expressão existencial de interioridade, relacional de reciprocidade e proposicional de responsabilidade, bem como descrevemos os entraves para sua prática. A pesquisa teve seu ponto de partida identificado pelo questionamento sobre 0 diálogo e sua importância no espaço educativo. A viabilidade para responder a esse desafio foi buscada, justamente, no contato e na interação com uma escola de ensino médio, que orientada por um currículo institucional, propõe conteúdos direcionados para "[...] favorecer uma prática pedagógica voltada para a lente da diversidade com produtores de cidadãos críticos em relação a diversas realidades e pontos de vista construídos" (DISTRITO FEDERAL, 2016, p. 20).

Contudo, quando ingressamos no universo estudantil, demo-nos conta de que a realidade que se apresentava estava bastante distante da proposta formulada. Não só estávamos longe da possibilidade de respondê-la, como também os argumentos que se colocaram nos momentos de troca com os estudantes - chamados aqui de rodas de conversa - nos surpreenderam.

Esses estudantes nos mostraram que o seu cotidiano está distanciado de uma mediação e prática pedagógica dialogada. Suas falas fram desabafos sobre como se tornaram sujeitos sem voz na escola ou uma maioria que não participa das decisões escolares cuja palavra não é ouvida. Seres sem vozes, pouco participativos e estranhos dentro da escola: um não-lugar, sem afetos e esperança. Isso foi um choque porque, de tão recorrentes, as falas pareciam parte de um roteiro de filme pedagógico, que, em algum momento, talvez, fosse acabar bem.

Porém, não foi isso que ocorreu. Quanto mais avançávamos na pesquisa, mais percebíamos que os estudantes careciam dessa escuta atenta, na qual seus registros tivessem acolhimento, e de direcionamento, no sentido de apontar possíveis resoluções, de modo especial para a recorrência de alguns assuntos e/ ou problemas apontados.

O silêncio oriundo da ausência ou ineficiência do diálogo no ambiente escolar nos fez refletir sobre qual o sentido da escola na atualidade. Parece-nos que, em tempos de processos polarizados, mais ainda, há uma necessidade premente de se estabelecer diálogos - na escola, nas salas de aulas, nas relações pessoais e coletivas - que não estejam na isenção dos sujeitos, mas na aproximação das subjetividades para multiplicação de forças capazes de tornar a escola mais que transmissora de conteúdos. 
Inspirados na pedagogia freireana, cuja práxis fundamenta-se na problematização, e coadunando os nossos estudos no diálogo como mediação pedagógica, esse recorte de pesquisa demonstrou que o diálogo, na educação, é mais do que uma necessidade humana e individual, é fonte de conhecimento, é princípio fundamental para a formação de identidades, é meio para a construção de debates com conteúdos capazes de conhecer o diverso, e é finalidade, quando implica formar cidadãos críticos e criativos e construir processos educacionais dialógicos. 


\section{REFERÊNCIAS}

ABRAMOVAY, Miriam; CUNHA, Ana Lúcia; CALAF, Priscila Pinto. Revelando traumas, descobrindo segredos: violência e convivência nas escolas. Brasília: SEDF, 2009. Disponível em: < http:// www.abglt.org.br/docs/Revelando_Tramas.pdf>. Acesso em: 23 jun. 2019.

AFONSO, M. L. M. (Org.). Oficinas em Dinâmica de Grupo: um método de intervenção psicossocial. São Paulo: Casa do Psicólogo, 2006.

AFONSO, M. L.; ABADE, F. L. Para reinventar as rodas: rodas de conversa em direitos humanos. Belo Horizonte: RECIMAM, 2008.

ARROYO. Miguel G. Outros sujeitos, Outras pedagogias. 2 ed. Petrópolis, RJ: Vozes, 2014.

BARDIN, Laurence. Análise do Contexto. Lisboa: Edições 70, 2009.

BENTO, Maria Aparecida Silva. Cidadania em Preto e Branco. São Paulo: Ática, 2006.

BUBER, M. Do diálogo e do dialógico. São Paulo: Perspectiva, 2009.

BUBER, M. Eu e Tu. Trad. e introd. Newton A von Zuben. 10 ed. São Paulo: Centauro, 2001.

CAMPOS, Gastão Walter de S. Um método para análise e cogestão de coletivos: a constituição do sujeito, a produção de valor de uso e a democracia em instituições: o método da roda. São Paulo: HUCITEC, 2010.

CAMPOS, Pedro Ortega. Educar perguntando: ajuda filosófica na escola e na vida. São Paulo: Paulinas, 2008.

CAVALLEIRO, Eliane. (Org.). Racismo e anti-racismo na educação: repensando nossa escola. São Paulo: Selo negro, 2001.

DISTRITO FEDERAL. Secretaria de Estado de Educação -SEDF. Currículo em movimento da educação básica. Pressupostos teóricos. Brasília, 2018.

. Secretaria de Estado de Educação - SEDF. Currículo em movimento da educação básica. Pressupostos teóricos. Brasília, 2018. Disponível em: <http://www.cre.se.df.gov.br/ascom/ documentos/subeb/cur_mov/1_pressupostos_teoricos.pdf >. Acesso em: 14 ago. 2019.

FREIRE, Paulo. Pedagogia da autonomia: Saberes necessários a prática educativa. São Paulo. Ed: Paz e Terra, 2011.

FREIRE, Paulo. Pedagogia da esperança. Um reencontro com a Pedagogia do oprimido. 12. ed. São Paulo: Paz e Terra, 2005.

FREIRE, Paulo. Pedagogia do oprimido. 40 ed. Rio de Janeiro, Paz e Terra, 2005

GADAMER, Hans-Georg. Verdade e Método II. Complementos e índice. Petrópolis, RJ: Vozes, 2002. 
GADOTTI, Moacir. Educação e Poder: introdução à pedagogia do conflito. 12. ed. São Paulo: Cortez, 2001.

GOFFMAN, Erving. Estigma: notas sobre a manipulação da identidade deteriorada. 4. ed. Rio de Janeiro: Guanabara, 2004.

GOMES, Nilma L. Diversidade cultural, currículo e questão racial. Desafios para a prática pedagógica. In: ABRAMOWICZ, Anete; BARBOSA, Maria de A.; Silvério, Valter R. (Orgs.). Educação como prática da diferença. Campinas, SP: Armazém do Ipê, 2006. p. 21-42.

PINTO, Regina P. A representação do negro em livros didáticos de leitura. Cadernos de Pesquisa. São Paulo, n. 63, p. 88-92, nov. 1987. Disponível em: < http://www.fcc.org.br/pesquisa/publicacoes/ cp/arquivos/659.Pdf>. Acesso em: 01 jun. 2019.

RAWLS, John. Teoria da justiça. Brasília: UnB, 2000.

ROSEMBERG, Fúlvia; BAZILLI, Chirley; SILVA, Vinicius Baptista da. Racismo em livros didáticos brasileiros e seu combate: uma revisão da literatura. Educação e Pesquisa, São Paulo, v. 29, n.1, p. 125-146, jan./jun., 2003. Disponível em:< http://www.scielo.br/pdf/ep/v29n1/a10v29n1.pdf>. Acesso em: 12 abr. 2019.

SILVA, Vinicius Baptista da. Racismo em livros didáticos: estudo sobre negros e brancos em livros de Língua Portuguesa. Belo Horizonte: Autêntica, 2008.

SOUZA, Ricardo Timm. Sobre a construção de sentido: o pensar e o agir entre a vida e a filosofia. São Paulo: Perspectiva, 2008.

TAYLOR, Charles. A ética da autenticidade. Lisboa, Portugal: Edições 70, 2009.

TEODORO, Maria de Lourdes. Identidade, cultura e educação. Cadernos de pesquisa, Fundação Carlos Chagas. n. 63, p.46-50, nov., 1987. Disponível em:< http://publicacoes.fcc.org.br/ojs/index. php/cp/article/view/1270/1271>. Acesso em: 12 maio 2019. 